Egyptian

Orthodontic Journal

\title{
The Skeletal Effect of Two Mandibular Expanders on the Mandibular Arch: a CBCT Comparative Study
}

\author{
Saif Alnaser A. Alsullei ${ }^{1}$, Al-Dany A Mohammed ${ }^{2}$ \\ Farouk A Hussein ${ }^{3}$, Abdullah M. Agniah ${ }^{4}$
}

\section{ABSTRACT:}

Objectives: The aim of this study was to evaluate and compare the skeletal and dentoalveolar effects of two different mandibular expansion appliances using cone beam computed tomography. Methods: The current randomized clinical study was conducted on a total sample of 20 orthodontic patients. The samples mean age $13.4 \pm 0.5$. CBCTs were taken before and after orthodontic expansion. The patients were divided in to two groups, group I: consisted 10 patients treated with Williams mandibular expander, group II: consisted 10 patients treated with skeletal mandibular expander. Results: The results showed high significant increase in all linear and angular parameter of the two mandibular expansion groups except the mandibular body width and mandibular incisor inclination. On comparison of the mean differences of treatment variables between both groups of mandibular expansion, dental and skeletal effects were not statistically different $(p>0.05)$. In contrast, the interpremolar width, intercanine width, and arch perimeter were significantly increased in skeletal expander group than the Williams one.

\section{INTRODUCTION}

Crowding in the mandibular arch is a common problem in most orthodontic patients. The amount of crowding in the mandibular arch is a critical factor in extraction decision. Since treatment strategies have been changed lately to more conservative approaches, nowadays, there is great interest in nonextraction alternatives for space gaining, particularly in borderline cases. Among these alternatives are; enamel stripping, distalization, and arch development through expansion.

Although expansion can be done successfully in the maxillary arch, in mandibular arch, the expansion treatment has been thought to be less effective and less stable in long term. This could be attributed to the anatomical limitations in the mandible, since, the maxilla has a midpalatal suture but the mandible has not; therefore, the effect of mandibular expansion was believed to be localized to the alveolar process and mainly produce tipping of the buccal segment. Nowadays, contradicting opinions exist regarding the effects and stability of mandibular expansion. Some reports have stated that, "The mandibular expansion is not stable and the mandibular arch form cannot be permanently altered by the appliance therapy", whereas other investigations have demonstrated that the mandibular arch width could be expanded permanently. Most of previous studies have evaluated the mandibular expansion by using posteroanterior cephalometric radiography in spite of its limitations which include projection errors, magnification, distortion, and the 2-dimensional representation of a three dimensional structure. Currently, these limitations have been resolved by using Cone Beam Computed Tomography (CBCT)

1- MSc in orthodontic Ministry of Health, Bani Waleed, Libya

2- Professor, and head of Orthodontic Department, Faculty of Dental Medicine (Boys) Al-Azhar University, Cairo, Egypt

3- Assistants professor, Faculty of Dental Medicine (Boys), Al-Azhar University, Cairo, Egypt

4- MSc in orthodontics Ministry of Health, Libya 
which is a 3- dimensional tool characterized by high resolution, high accuracy, minimum distortion, and lower radiation dose. Although, many reports have been published regarding maxillary expansion, little has been reported in literature about the expansion in the mandibular arch. In view of the limited available literature, it is a matter of interest to clarify and analyze the changes occurring in the mandibular arch concomitant to expansion using two different mandibular expanders.

\section{MATERIALS \& METHODS}

The current randomized clinical study was conducted on a total sample of 20 orthodontic patients randomly selected from a large pool of patients who were seeking treatment at outpatient clinic, Orthodontic Department, Faculty of Dental Medicine (boys), AL-Azhar University; Cairo. Sample size calculation was based on a power statistical analysis as follows: For an alpha error of 0.05 and power of $95 \%$, the minimum sample size required was estimated to be 20 patients, 10 patients in each arm. The patients were randomly divided into two equal groups (10 patients each) according to the type of the mandibular expander Group I: included 10 patients treated with Williams mandibular expander, A suitable size $(8 \mathrm{~mm})$ jack screw was used for all patients, and the expander appliance was fabricated on the mandibular model. The screw was placed at the middle of lingual region of the mandible. In William's expander, the two arms were placed parallel to the occlusal line on the cervical third of the mandibular canines and premolars teeth and soldered to the lingual surface of the 1st molar bands. Group II: included 10 patents treated with skeletal mandibular expander. The only difference is that, in the skeletal expander the two arms of the expander were placed more apically $(4-6 \mathrm{~mm}$ ) below the gingival margin. 67 The two arms of skeletal expander were adapted and relieved from the underlying tissue by about $1.5 \mathrm{~mm}$ to prevent tissue damage. One $\mathrm{mm}$ stainless wire is placed on the cervical third from canine to second molar. The arms of the expander together with the lingual wire were soldered to the middle of the lingual surfaces of the 1st molar bands. The appliance was then polished, and the bands were cemented using glass ionomer cement. The process of randomization and group allocation was undertaken via a computerized simple online generated randomization plan. Using online software using online software found at the web site: http://www.graphpad.com/quickcalcs/randomize.

\section{Steps of constructing expansion appliances:}

\section{Williams expander:}

Separation: Elastic separators were placed mesial and distal to the mandibular first permanent molar and left in place for three days. Banding: A suitable stainless steel ready-made band 0.006 inch thickness and 0.2 inch width were selected and directly fitted on the mandibular first permanent molar bilaterally. Impressions: An impression was taken with alginate impression material the impression was allowed five minutes to set in the patient mouth, then removed, then seated in the correct position on the impression. A few drops of molten waxwere used to fix the bands in place during pouring. A suitable size $(8 \mathrm{~mm})$ jack screw was used for all patients, and the expander appliance was fabricated on the mandibular model. The screw was placed at the middle of lingual region of the mandible. In William's expander, the two arms were placed parallel to the occlusal line on the cervical third of the mandibular canines and premolars teeth and soldered to the lingual surface of the $1^{\text {st }}$ molar bands.

\section{Skeletal expander appliance:}

All the steps previously mentioned for William's expander were undertaken in the 
same manner. The only difference is that, in the skeletal expander the two arms of the expander were placed more apically (4-6 $\mathrm{mm}$ ) below the gingival margin. ${ }^{1}$ The two arms of skeletal expander were adapted and relieved from the underlying tissue by about $1.5 \mathrm{~mm}$ to prevent tissue damage. One mm stainless wire is placed on the cervical third from canine to second molar.

Activation of the appliance: For each patient involved in the study, the activation was initiated on the day of appliance insertion. The same activation protocol was followed for both William's and skeletal expanders. Patients were instructed to turn the screw one quarter turn twice/week ${ }^{2}$ The expansion was continued for 3-4 months

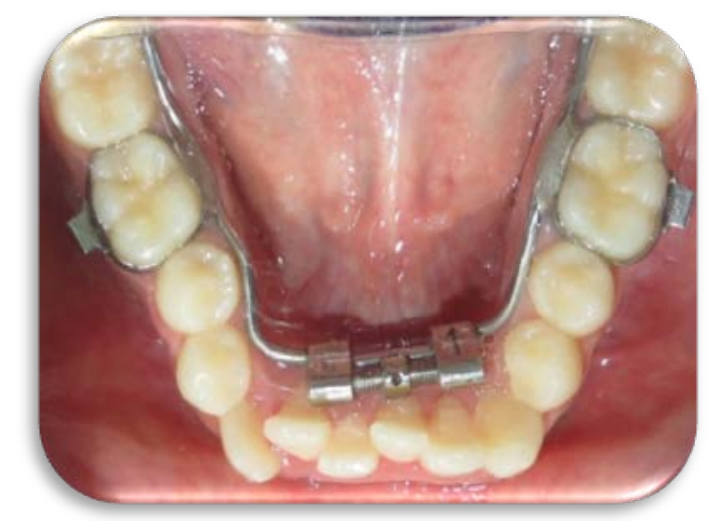

Figure 1: Occlusal view showing William's Expander

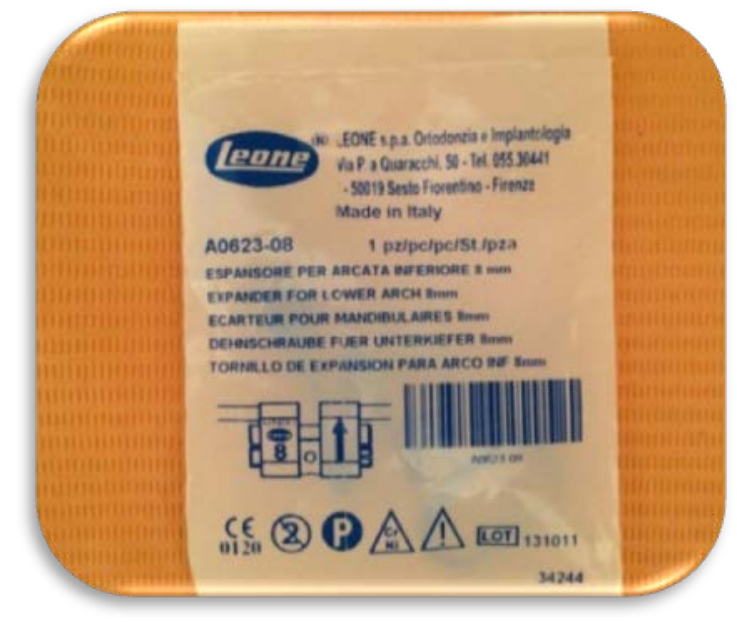

Figure 3: expansion screw package

\section{Cone beam Computed tomography:}

The CBCT images were acquired using a Planmeca Promax scanner. A scout view was obtained and adjustments were made to ensure that all patients were correctly aligned in the scanner according to adjustment light beam before acquisition. The machine was supplied with Amorphous Silicon Flat Panel Sensor. A wooden spatula was placed between the jaws to avoid occlusal contact. After acquisition, data were exported and transferred in DICOM format and downloaded via a Compact Disk (CD) to a personal computer for linear measurements, where in vivo Dental software was utilized. Serial of steps were followed to standardize the measurements in all scans.

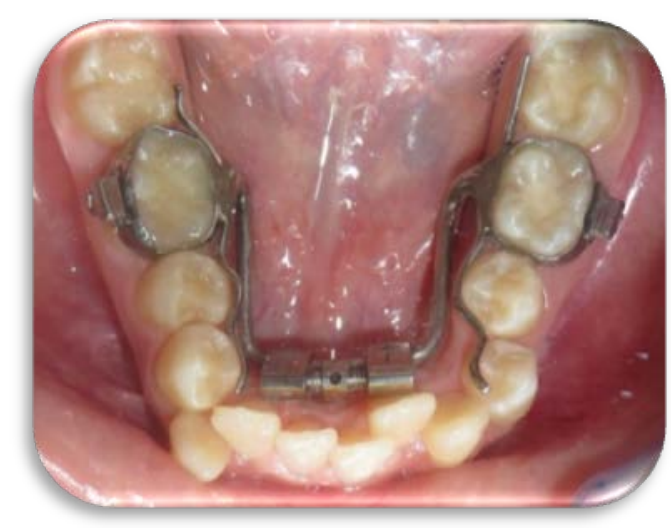

Figur2: Occlusal view showing Skeletal expander

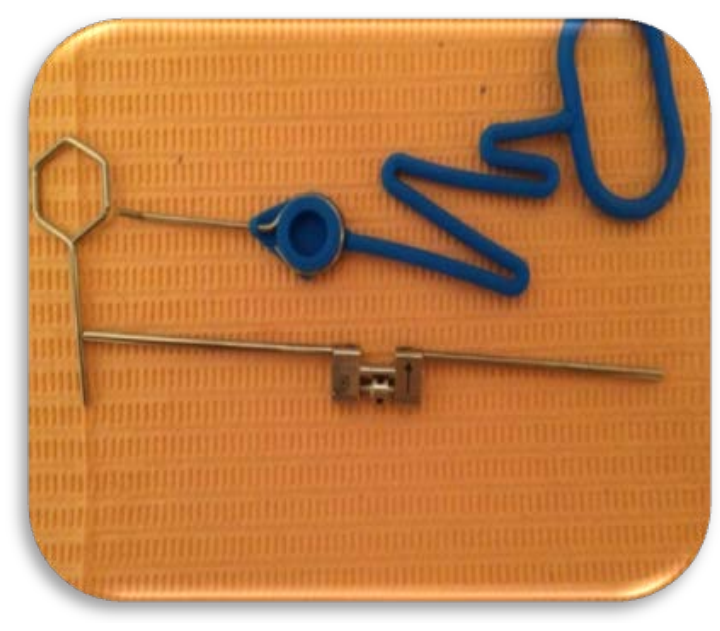

Figure 4: mandibular arch expansion screw 


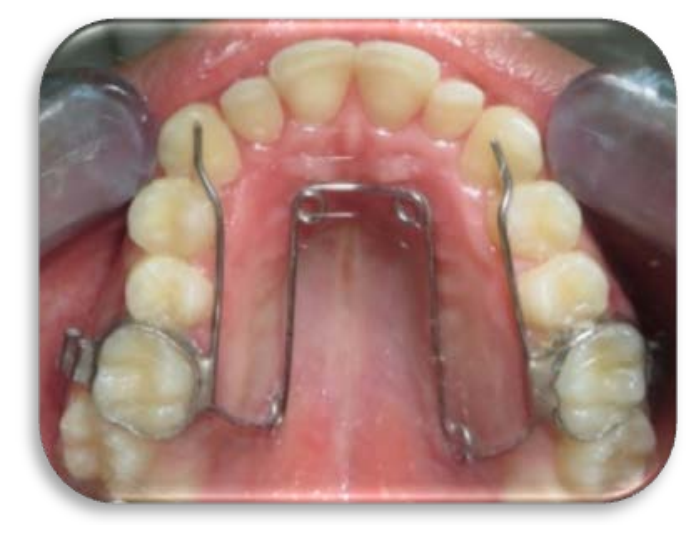

Figure 5: occlusal view showing Quad helix expander

\section{The first step; superimposition:}

The set of Dicom data of the preoperative scan is loaded into the software, and then the set of the postoperative scan of the same patient was loaded over it.

According to the variation in positioning of both scans, a second adjustment was needed to ensure perfect superimposition, hence guaranteeing measuring linear and angular measurements at the exact level. Superimposition module was used to superimpose the postoperative scan over the preoperative one (Fig.7), where three landmarks at different anatomical areas were chosen at each scan, menton, right and left gonions, and then registration of these landmarks was automatically performed by the software. Superimposition sequence was repeated for each patient individually.

\section{The second step; Orientation:}

After completion of superimposition, the two scans (preoperative and postoperative) were one unit and move in the same sequence (Fig. 8). Orientation of the whole volume was made to ensure that the orthogonal reference lines (axial, coronal and sagittal) would intersect at the area of interest for each

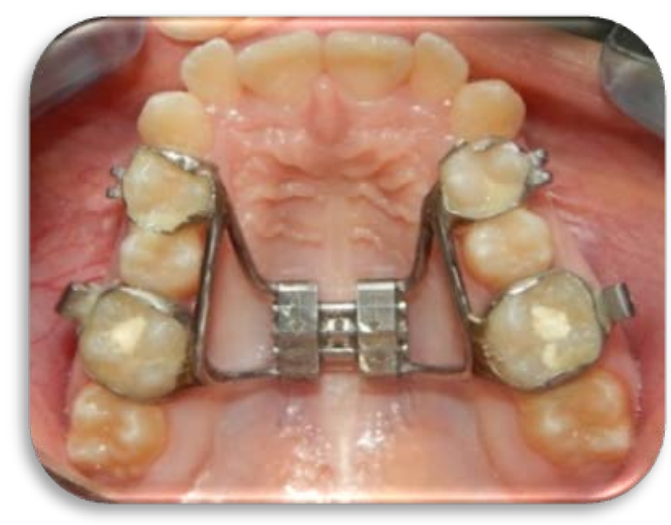

Figure 6: occlusal view showing Hyrax expander

measurement (for both $\mathrm{T} 1$ and $\mathrm{T} 2$ scans), where adjustment of each measurement was made individually and repeated in the same manner in each scan. Certain reference plane was to be assigned, according to which the measurements would be taken. Mandibular plane was selected for this purpose. In order to assign mandibular plane, three points were identified at the level of the lower border of mandible; menton anteriorly, right and left gonion posteriorly axial, coronal and sagittal views was obtained.

Constructed mandibular plane is now a common plane for both preoperative and postoperative scans, since changing the level of the viewed section at axial, coronal or sagittal plane, would not change the location of mandibular plane, since the orientation of the volume data was saved.

After superimposition and orientation is complete, the two scans were viewed by the software either separately or superimposed, where the software allowed viewing either one set data solely or both data at the same time, while reference lines remain at the same levels for both scans, regardless to which scan data was viewed. 


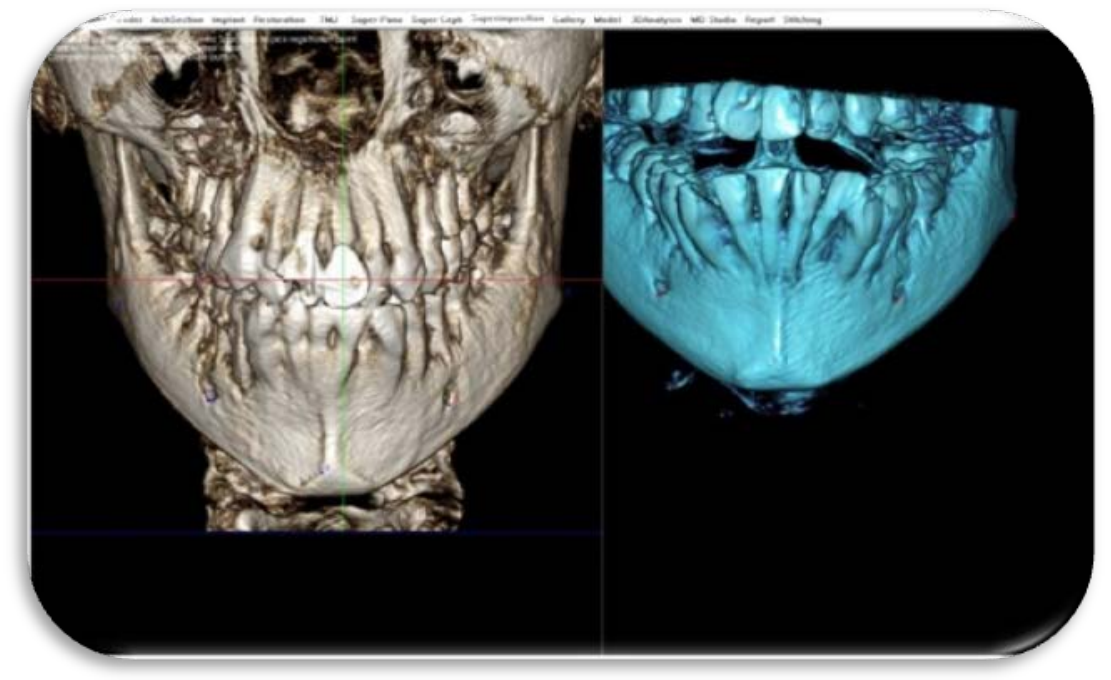

Figure 7: Pre and post expansion CBCT images before superimposition.

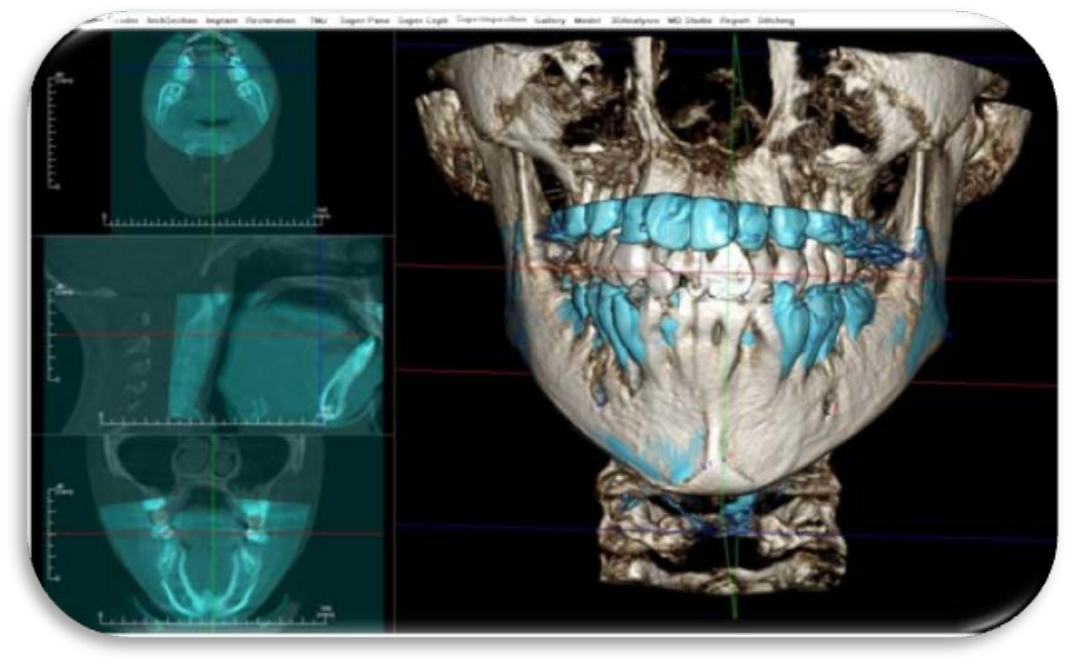

Figure 8: Pre and post expansion CBCT images after superimposition.

\section{STATISTICAL ANALYSIS}

Descriptive statistics were done for all CBCT variables for both groups. Data were presented as mean, standard deviation (SD) standard error of mean (SE), and 95\% Confidence Interval (95\% CI) for the mean values. Numerical data were explored for normality by checking the distribution of data using tests of normality Kolmogorov-Sminrov and Shapiro Wilk tests. Error analysis was done, where all measurements were repeated by the same investigator for 8 randomly selected cases ( $40 \%$ of the total sample),
4 patients from each group, at 3-week intervals. Intra-examiner reliability of measurements was assessed by comparing the first measurements taken from the whole sample to the second measurements taken from $40 \%$ of the sample using paired sample t-test. Comparison the effects of expansion within each group were performed via paired t-tests to compare CBCT dentoskeletal measurements before expansion (T1) and after expansion (T2). Additionally, independent sample t-test was used to compare these variables between both groups. The significance level was set at $\mathrm{p} \leq 0.05$. 
All statistical analyses were performed using the $\mathrm{IBM}^{\circledR}$ Statistical Package for Social Science (SPSS) Version 23 for Windows.

\section{RESULTS}

Normality check: For analysis of distribution of data in the present study, Kolmogorov-Smirnov and Shapiro-Wilk tests were used. They revealed normal distribution of the data and parametric tests for comparison were also used.

\section{Analysis of error of measurements:}

To determine the intra-examiner error of measurements, paired sample $t$-test was conducted for the mean difference between the first measurements (data of the total sample) and the $2^{\text {nd }}$ measurements (data of $40 \%$ of the sample). They demonstrate no statistically significant difference between $1^{\text {st }}$ and $2^{\text {nd }}$ measurements.

\section{Comparison of the expansion effects between two groups:}

\section{a- Dental measurements:}

Table 1 shows the comparison between two expander groups, regarding mandibular linear and angular $1^{\text {st }}$ molar measurements using independent sample $t$-test. There are statistically non-significant differences in the amount of increase of mandibular $1^{\text {st }}$ molar variables between groups. Table 2: shows the comparison between the two expanders concerning linear and angular $1^{\text {st }}$ premolar CBCT measurements using independent sample $t$-test. There are no statistically significant differences for the measurements of cementoenamel junction $\left(\mathrm{CEJ} 4_{\mathrm{L}}\right)$, the distance between first premolar root $\left(\mathrm{R} 4_{\mathrm{L}}\right)$, and right and left first premolar inclinations $\mathrm{RPM}^{\circ}$ and $\mathrm{LPM}^{\circ}$. However, the change of the interpremolar width (MIPW) is significantly increased in the skeletal expander than the William's expander. Table 3: shows comparison between both groups for CBCT mandibular intercanine width (MICW), arch perimeter (AP), and mandibular incisor inclination $\left(\mathrm{Li}^{\circ}\right)$ using independent sample $t$-test. The changes of MICW and AP are significantly increased in the skeletal expander group than the William's expander one. However, the changes of the $\mathrm{Li}$ ${ }^{\circ}$ in both groups of expansion are not statistically significant.

\section{b- Skeletal measurements:}

Table 4 shows comparison between the two groups regarding the skeletal effects of both types of mandibular expander using Independent sample $t$-test. There are no significant differences between two groups $(p>0.05)$.

Table1: Descriptive statistics and test of significance (independent sample $t$-test) for the mean expansion differences in linear and angular $1^{\text {st }}$ molar measurements between groups.

\begin{tabular}{|c|c|c|c|c|c|c|c|c|c|c|}
\hline \multirow[b]{2}{*}{ Variable } & \multicolumn{3}{|c|}{ Group A } & \multicolumn{3}{|c|}{ Group B } & \multicolumn{4}{|c|}{ Independent sample t-test } \\
\hline & 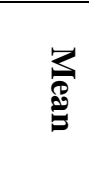 & ص & 虽 & 富 & 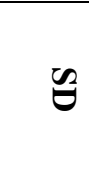 & 告 & 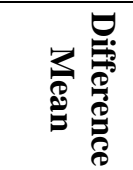 & 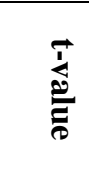 & 茫 & مִ \\
\hline MIMW & 5.30 & 1.69 & 0.64 & 6.88 & 2.17 & 0.72 & 1.58 & 1.59 & 0.134 & NS \\
\hline MBCT6 $_{L}$ & 5.44 & 1.85 & 0.70 & 7.10 & 1.63 & 0.54 & 1.66 & 1.89 & 0.079 & NS \\
\hline CEJ6 $_{L}$ & 3.90 & 1.05 & 0.39 & 4.72 & 1.51 & 0.50 & 0.82 & 1.23 & 0.239 & NS \\
\hline MR6 $_{L}$ & 2.47 & 1.42 & 0.54 & 2.30 & 0.48 & 0.16 & 0.17 & 0.30 & 0.076 & NS \\
\hline $\mathbf{R M}^{\circ}$ & 7.94 & 2.36 & 0.89 & 9.07 & 2.64 & 0.88 & 1.13 & 0.90 & 0.388 & NS \\
\hline $\mathbf{L M}^{\circ}$ & 9.50 & 3.86 & 1.46 & 12.5 & 3.33 & 1.11 & 3.45 & 0.22 & 0.827 & NS \\
\hline
\end{tabular}


Table 2: Descriptive statistics and test of significance (independent sample $t$-test) for the mean expansion differences in linear and angular $1^{\text {st }}$ premolar CBCT measurements between both groups

\begin{tabular}{|c|c|c|c|c|c|c|c|c|c|c|}
\hline \multirow[b]{2}{*}{ Variable } & \multicolumn{3}{|c|}{ Group A } & \multicolumn{3}{|c|}{ Group B } & \multicolumn{4}{|c|}{ Independent sample $t$-test } \\
\hline & 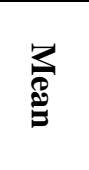 & $g$ & 邹 & 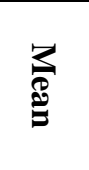 & $g$ & 的 & 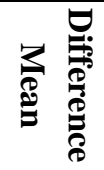 & 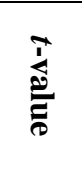 & & $\stackrel{n}{\alpha a}$ \\
\hline MIPW & 4.19 & 1.68 & 0.64 & 7.01 & 1.40 & 0.46 & 2.82 & 3.58 & 0.04 & × \\
\hline $\mathrm{BCT4}_{\mathrm{L}}$ & 5.67 & 1.83 & 0.69 & 7.38 & 1.70 & 0.56 & 1.71 & 1.92 & 0.78 & NS \\
\hline $\mathrm{CEJ}_{\mathrm{L}}$ & 4.04 & 1.68 & 0.63 & 5.37 & 2.13 & 0.71 & 1.33 & 1.40 & 0.18 & NS \\
\hline $\mathbf{R} \mathbf{4}_{\mathbf{L}}$ & 1.91 & 1.02 & 0.39 & 2.76 & 1.51 & 0.50 & 0.85 & 1.34 & 0.20 & NS \\
\hline $\mathbf{R P M}^{\circ}$ & 7.94 & 3.63 & 1.37 & 12.2 & 3.79 & 1.26 & 4.26 & 2.26 & 0.40 & NS \\
\hline $\mathbf{L P M}^{\circ}$ & 9.10 & 3.25 & 1.23 & 12.5 & 3.24 & 1.22 & 3.45 & 2.08 & 0.06 & NS \\
\hline
\end{tabular}

Table 3: Descriptive statistics and test of significance (independent sample $t$-test) for the mean expansion differences in mandibular intercanine width, arch perimeter and incisor inclination between both groups.

\begin{tabular}{|c|c|c|c|c|c|c|c|c|c|c|}
\hline \multirow[b]{2}{*}{ Variable } & \multicolumn{3}{|c|}{ Group A } & \multicolumn{3}{|c|}{ Group B } & \multicolumn{4}{|c|}{ Independent sample $t$-test } \\
\hline & $\begin{array}{l}\text { 3) } \\
\text { 总 }\end{array}$ & $g$ & 年 & $\begin{array}{l}\text { 葛 } \\
\text { 严 }\end{array}$ & $g$ & 足 & 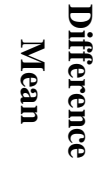 & $\frac{\bar{T}}{\stackrel{\tilde{d}}{\tilde{\partial}}}$ & 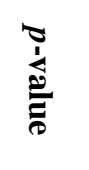 & $\stackrel{n}{a ̣}$ \\
\hline MICW & 1.50 & 0.76 & 0.29 & 3.17 & 1.71 & 0.57 & 1.67 & 2.62 & 0.03 & * \\
\hline $\mathbf{A P}$ & 4.57 & 1.64 & 0.62 & 8.27 & 3.23 & 1.07 & 3.71 & 2.97 & 0.01 & ${ }^{x}$ \\
\hline $\mathbf{L i}^{\circ}$ & 2.01 & 4.23 & 1.59 & 1.60 & 3.29 & 1.09 & 0.41 & 0.22 & 0.82 & NS \\
\hline
\end{tabular}

Table (4): Descriptive statistics and test of significance (independent sample $t$-test) for the mean expansion differences in skeletal CBCT measurements between both groups.

\begin{tabular}{|c|c|c|c|c|c|c|c|c|c|c|}
\hline \multirow[b]{2}{*}{ Variable } & \multicolumn{3}{|c|}{ Group A } & \multicolumn{3}{|c|}{ Group B } & \multicolumn{4}{|c|}{ Independent sample $t$-test } \\
\hline & 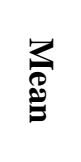 & g & 勿 & \begin{tabular}{l}
3 \\
3 \\
\multirow{2}{*}{}
\end{tabular} & g & 勿 & 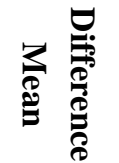 & $\frac{\bar{T}}{\stackrel{\tilde{J}}{\tilde{J}}}$ & & $\stackrel{n}{a}$ \\
\hline BDAW6 $_{L}$ & 1.04 & 0.89 & 0.34 & 1.66 & 0.90 & 0.30 & 0.62 & 1.36 & 0.19 & NS \\
\hline OMBW6 $_{L}$ & 0.54 & 0.73 & 0.28 & 0.46 & 0.46 & 0.15 & 0.08 & 0.23 & 0.81 & NS \\
\hline
\end{tabular}

\section{DISCUSSION}

The amount of crowding in the mandibular arch is often a critical factor in the decision of whether to extract teeth. In non-extraction approach, resolution of crowding could be achieved by several methods such as distalization, proclination of anterior teeth or expanding the dental arch transversely. ${ }^{3}$ How much crowding can be resolved with expansion of teeth and how much of expansion will be stable should be considered. ${ }^{4}$ Currently, there is a well-established phenomenon about the correlation between the collapsed arch widths and crowding of mandibular arch. This has been established through several comparatives studies between the crowded and well aligned dental arches, most of these studies correlated 
the crowded mandibular arch to the deficient arch width, rather than collective arch length to tooth material discrepancy. ${ }^{5,6,7}$ Although several mandibular lingual expansion appliances have been utilized to increase the transverse dimension of the mandibular arch, unfortunately, none of them succeed in producing a skeletal effect. $^{4,2,8,9,10,11}$

\section{Dental effects of mandibular expanders:}

\section{A- Intermolar width.}

Intermolar width has been the most frequent measure of posterior arch dimension following expansion. ${ }^{12}$ In the current study, comparison of before expansion (T1) to after expansion (T2) intermolar width measurements has indicated that both type of expanders produced significant buccal molar tipping.

It was noted that the increase in the transverse dimensions at mandibular first molars showed the highest values at the cusp tips and modest values at the CEJ and the least values at $7 \mathrm{~mm}$ below CEJ. Recently, several CBCT studies $^{9-11}$ assessed the changes in dentoalveolar inclination of mandibular $1^{\text {st }}$ molars in patients treated with removable Schwarz expander at different levels. Although, these changes were somewhat smaller than those reported in the present study, the little difference observed may be due to difference in methodology, since they used different expander. Regarding the amount of mandibular first molar expansion, the current results agree with the data from the study of Motoyoshi et al., ${ }^{13,14}$ who evaluated mandibular expansion using removable Schwarz expanders with a 3D finite element method (FEM). In addition, Housley et al., investigated the effects of fixed mandibular lingual. The results were much smaller than those of the current study.

\section{B- Inter first premolar width:}

In the current study, there was a significant increase in the inter-first premolar width following mandibular expansion with
William's expander and a highly significant increase with skeletal expanders. These results are in agreement with those found by Housley et al., ${ }^{4}$ who reported a significant increase in interpremolar width with fixed mandibular expander. The findings of current study are also in agreement with those of Handelman ${ }^{1}$ who reported a significant increase in the interpremolar width by fixed mandibular two arm expander.

\section{C- Intercanine width:}

The intercanine width in the present study was significantly increased in both groups.

These results are in accordance with several studies ${ }^{4,}$ 2, 11, 15,16 which used different types of mandibular expanders. Hamula ${ }^{15}$ reported an average expansion of $4.5 \mathrm{~mm}$ in intercuspid width with modified mandibular Schwarz appliance in an eight years old girl, but this finding cannot be directly compared to the results of the present study because it was a case report conducted on only one patient. Housley et al., ${ }^{4}$ reported average increase in intercanine width of $1.52 \mathrm{~mm}$. These finding is comparable with the present study for William's expander group, however it was smaller than those reported for the skeletal expander group. Busdrang et al., ${ }^{2}$ examined the mandibular arch expansion with removable Schwarz appliance and lip bumper. They have shown that the intercanine width increased significantly more with the REA (3.1 mm) than the $\mathrm{LB}(1.3 \mathrm{~mm})$. The results of REA are concurring with the findings in the skeletal expander group, however, the results with LB was comparable with William's expander but was smaller when compared with skeletal expander. Sabuncuoglu et al., ${ }^{16}$ noted an increase in the intercanine width by $1.2 \mathrm{~mm}$ after mandibular expansion with trombone fixed expander. This finding concurs with the present results for William's group but was smaller than that reported for skeletal expander. 


\section{D- Incisor inclination:}

The current results revealed nonsignificant increase in incisor inclination following mandibular arch expansion with both William's and skeletal expanders. Several authors reported an increase in the mandibular incisor inclination following expansion. ${ }^{2,4,17}$

\section{E-Arch perimeter:}

In the present investigation, the arch perimeter increased significantly in both mandibular expansion groups. Several studies have reported an increase in the arch perimeter following mandibular expansion. 1,3,4,9, 10, 13,14,16, 18,19 These findings agree with the present results. Although such investigations have utilized different sample age, expanders design methods of evaluation, and treatment duration.

\section{Skeletal effects of mandibular expanders:}

The results of the current study showed almost a similar effect of both expanders concerning skeletal effects. These findings revealed no significant difference between both groups. The present study demonstrated that the mandibular bodies were not affected by the skeletal and William's expander appliances in spite of the observed dentoalveolar expansion. The transverse dimension has been a focus of controversy among orthodontists. ${ }^{20}$ Kusnoto et al., ${ }^{21}$ examined 60 orthodontically treated subjects with transverse asymmetries in arch width and found that the transverse arch form was not corrected with routine orthodontic treatment. These observations agreed with the dogma in orthodontics that arch form cannot be altered. Therefore, any change in mandibular arch form is unrealistic and would be difficult to retain. ${ }^{22}$ The results of Tai et al., ${ }^{9-11}$ were closer to the present study regarding skeletal effects of mandibular expansion using Schwarz expander via CBCT evaluation. Although the mandibular arch expanded mainly by tooth inclination, the distance between the root tips also increased. Furthermore, the amounts of displacement of alveolar bone were almost the same on the buccal and lingual sides. Additionally, Hamada et al., ${ }^{23}$ reported that the alveolar process changed with mandibular expansion in an animal experiment. However no effect was induced by the Schwarz appliance in the alveolar base and mandibular bodies. In contrast, the study of Robert et al., ${ }^{24}$ reported that the lip bumper significantly increased the mandibular transverse skeletal dimension. These findings disagree with the results of present study that could be due to different methods of evaluation by 2D conventional posteroanterior cephalometric radiographs.

\section{REFERENCES}

1. Handelman CS, Adult non-surgical maxillary and concurrent mandibular expansion; Treatment of maxillary transverse deficiency and bidental arch constriction. Semin Orthod 2012;18:134-51.

2. Busdrang PH, Horton-Reuland SJ, Legler L, Nevant C. Nonextraction approach to tooth size archlength discrepancies with the Alexander discipline. In: Seminars in Orthodontics. Elsevier; 2001. p. 117-31.

3. Weinberg M, Sadowsky C. Resolution of mandibular arch crowding in growing patients with Class I malocclusions treated nonextraction. Am J Orthod Dentofac Orthop. 1996;110:359-64.

4. Housley JA, Nanda RS, Currier GF, McCune DE. Stability of transverse expansion in the mandibular arch. Am J Orthod Dentofac Orthop. 2003;124:288-93.

5. Sanin C, Savara BS. Factors that affect the alignment of the mandibular incisors: a longitudinal study. Am J Orthod. 1973;64: 248-57. 
6. Radnzic D. Dental crowding and its relationship to mesiodistal crown diameters and arch dimensions. Am J Orthod Dentofac Orthop. 1988;94:50-6.

7. Hagberg C. The alignment of permanent mandibular incisors in children. A longitudinal prospective study. Eur J Orthod. 1994;16:121-9.

8. Brennan MM, Gianelly AA. The use of the lingual arch in the mixed dentition to resolve incisor crowding. Am J Orthod Dentofac Orthop. 2000;117:81-5.

9. Tai K, Hotokezaka H, Park JH, Tai H, Miyajima K, Choi M, et al. Preliminary cone-beam computed tomography study evaluating dental and skeletal changes after treatment with a mandibular Schwarz appliance. Am J Orthod Dentofac Orthop. 2010;138:262-e1.

10. Tai K, Park JH. Dental and skeletal changes in the upper and lower jaws after treatment with Schwarz appliances using cone-beam computed tomography. J Clin Pediatr Dent. 2010;35:111-20.

11. Tai K, Park JH, Mishima K, Shin J-W. 3-Dimensional cone-beam computed tomography analysis of transverse changes with Schwarz appliances on both jaws. Angle Orthod. 2011;81:670-7.

12. Rogers AP. Making facial muscles our allies in treatment and retention. Dent Cosm. 1922;64: 711-30.

13. Motoyoshi M, Hirabayashi M, Shimazaki T, Namura S. An experimental study on mandibular expansion: increases in arch width and perimeter. Eur J Orthod. 2002;24:125-30.

14. Hemanth M, Patil C, Sunilkumar P, Raghuveer HP, Chandralekha B. An experimental study of arch perimeter and arch width increase with mandibular expansion: a finite element method. J Contemp Dent Pract. 2013;14:104.
15. Hamula W. Modified mandibular Schwarz appliance. J Clin Orthod JCO. 1993;27:89-93.

16. Sabuncuoglu FA, Karacay S, Olmez H. Expansion of the mandibular arch using a trombone appliance. Korean J Orthod. 2011;41:211-8.

17. Maki K, Sorada Y, Ansai T, Nishioka T, Braham R, Konoo T. Expansion of the Mandibular Arch in Children during the Mixed Dentition Period-A Clinical Study. J Clin Pediatr Dent. 2006;30:329-32.

18. O’Grady PW, McNamara JA, Baccetti T, Franchi L. A long-term evaluation of the mandibular Schwarz appliance and the acrylic splint expander in early mixed dentition patients. Am J Orthod Dentofac Orthop. 2006;130:202-13.

19. Osborn WS, Nanda RS, Currier GF. Mandibular arch perimeter changes with lip bumper treatment. Am J Orthod Dentofac Orthop. 1991;99:527-32.

20. Schiffman PH, Tuncay OC. Maxillary expansion: a meta-analysis. Clin Orthod Res 2001; 4:86-96.

21. Kusnoto J, Evans CA, BeGole EA, Obrez A. Orthodontic correction of transverse arch asymmetries. Am J Orthod Dentofacial Orthop 2002;121:38-45.

22. Merrifield LL. Dimensions of the denture: back to basics. Am J Orthod Dentofacial Orthop 1994;106:535-42.

23. Hamada N, Ogihara K, Aiyama S. Effects of an expansion plate containing an expansion screw on the mandibular dental arch in beagles. Jpn J Pediatr Dent 2002;40:531-40.

24. Vanarsdall Jr RL, Secchi AG, Chung C-H, Katz SH. Mandibular basal structure response to lip bumper treatment in the transverse dimension. Angle Orthod. 2004;74:473-9. 